\title{
Transitivity and intransitivity in evidential support: Some further results
}

William Roche

Department of Philosophy, Texas Christian University, Fort Worth, TX, USA, e-mail: w.roche@tcu.edu

ABSTRACT: Igor Douven establishes several new intransitivity results concerning evidential support. I add to Douven's very instructive discussion by establishing two further intransitivity results and a transitivity result.

Igor Douven (2011) establishes several new intransitivity results concerning evidential support. I aim to add to Douven's very instructive discussion by establishing two further intransitivity results (sections 1 and 2) and a transitivity result (section 3 ).

1. Douven distinguishes between (i) evidence, (ii) t-evidence, (iii) t'-evidence, and (iv) tt'-evidence. $E$ is evidence for $H$ iff: $\operatorname{Pr}(H \mid E)>\operatorname{Pr}(H)$. $E$ is t-evidence for $H$ iff: (a) $E$ is evidence for $H$ and (b) $\operatorname{Pr}(H \mid E)>\mathbf{t}$. Here $\mathbf{t}$ is some specified value less than 1 and greater than or equal to .5. $E$ is t'-evidence for $H$ iff: (a) $E$ is evidence for $H$ and (b) either $\operatorname{Pr}(H \mid E)-\operatorname{Pr}(H)>\mathbf{t}^{\prime}$ or $\operatorname{Pr}(H \mid E)=1$. Here $\mathbf{t}^{\prime}$ is some specified value less than 1 and greater than 0. $E$ is $\mathbf{t t}^{\prime}$-evidence for $H$ iff: (a) $E$ is t-evidence for $H$ (hence is evidence for $H$ ) and (b) $E$ is t'-evidence for $H$.

It is well known that evidence (as defined above) is intransitive- that there are cases in which $\operatorname{Pr}(Q \mid R)>\operatorname{Pr}(Q), \operatorname{Pr}(P \mid Q)>\operatorname{Pr}(P)$, and yet it is not the case that $\operatorname{Pr}(P \mid R)>$ $\operatorname{Pr}(P) .{ }^{1}$ Douven shows that regardless of the values specified for $\mathbf{t}$ and $\mathbf{t}$ ' (but given the constraint that $1>\mathbf{t} \geq .5$ and $1>\mathbf{t}^{\prime}>0$ ) $\mathbf{t}$-evidence, $\mathbf{t}^{\prime}$-evidence, and $\mathbf{t t}^{\prime}$-evidence too are intransitive. So, where, for example, the value specified for $\mathbf{t}$ is .5 there are probability distributions on which $\operatorname{Pr}(Q \mid R)>\operatorname{Pr}(Q), \operatorname{Pr}(Q \mid R)>.5, \operatorname{Pr}(P \mid Q)>\operatorname{Pr}(P), \operatorname{Pr}(P \mid Q)>.5$, and yet $\operatorname{Pr}(P \mid R) \ngtr \operatorname{Pr}(P)$ or $\operatorname{Pr}(P \mid R) \ngtr$. . $^{2}$

Tomoji Shogenji (2003) shows that, though evidence (or "probabilistic support") is intransitive, there is a condition for transitivity in evidence. The condition is:

\footnotetext{
${ }^{1}$ See, e.g., Eells and Sober (1983, pp. 43-44), Hanen (1971), Hesse (1970, pp. 50-51), and Shogenji (2003, p. 613).

${ }^{2}$ Further, Douven shows that certain alternatives to $\mathbf{t}^{\prime}$-evidence and $\mathbf{t t}$ '-evidencealternatives involving not the difference measure of confirmation but, for example, the log-likelihood measure or the Kemeny-Oppenheim measure - are intransitive.
} 
(C)

$$
\operatorname{Pr}(P \mid R \wedge Q)=\operatorname{Pr}(P \mid Q) \text { and } \operatorname{Pr}(P \mid R \wedge \neg Q)=\operatorname{Pr}(P \mid \neg Q)
$$

Shogenji thus establishes the principle:

$$
\begin{aligned}
& \text { If } \operatorname{Pr}(Q \mid R)>\operatorname{Pr}(Q), \operatorname{Pr}(P \mid Q)>\operatorname{Pr}(P) \text {, and }(\mathrm{C}) \text { holds, then } \operatorname{Pr}(P \mid R)> \\
& \mathrm{P}(P){ }^{3}
\end{aligned}
$$

Douven shows that regardless of the values specified for $\mathbf{t}$ and $\mathbf{t}^{\prime}(\mathrm{C})$ is not a condition for transitivity in t-evidence, $\mathbf{t}$ '-evidence, or tt' '-evidence. Thus where, say, the value specified for $\mathbf{t}$ is .5 there are probability distributions on which $\operatorname{Pr}(Q \mid R)>\operatorname{Pr}(Q)$, $\operatorname{Pr}(Q \mid R)>.5, \operatorname{Pr}(P \mid Q)>\operatorname{Pr}(P), \operatorname{Pr}(P \mid Q)>.5,(C)$ holds, and yet $\operatorname{Pr}(P \mid R) \ngtr \operatorname{Pr}(P)$ or $\operatorname{Pr}(P \mid R) \ngtr .5$. $^{4}$

Consider the condition:

$$
\operatorname{Pr}(P \mid R \wedge Q) \geq \operatorname{Pr}(P \mid Q) \text { and } \operatorname{Pr}(P \mid R \wedge \neg Q) \geq \operatorname{Pr}(P \mid \neg Q) \text {. }
$$

$\left(\mathrm{C}^{*}\right)$ is weaker than $(\mathrm{C})$, in that if $(\mathrm{C})$ holds, then $\left(\mathrm{C}^{*}\right)$ holds, but not vice versa.

Elsewhere (Roche 2012) I establish the principle:

(TE*) If $\operatorname{Pr}(Q \mid R)>\operatorname{Pr}(Q), \operatorname{Pr}(P \mid Q)>\operatorname{Pr}(P)$, and $\left(\mathrm{C}^{*}\right)$ holds, then $\operatorname{Pr}(P \mid R)>$ $\mathrm{P}(P)$.

$\left(\mathrm{TE}^{*}\right)$ is stronger than (TE); if (TE*) is correct, then (TE) is correct, but not vice versa.

$\left(\mathrm{C}^{*}\right)$ holds if $(\mathrm{C})$ holds. So, given that regardless of the value specified for $\mathbf{t}$ there are probability distributions on which $R$ is t-evidence for $Q, Q$ is t-evidence for $P$, (C) holds, and yet $R$ is not $\mathbf{t}$-evidence for $P$, it follows that regardless of the value specified for $\mathbf{t}$ there are probability distributions on which $R$ is $\mathbf{t}$-evidence for $Q, Q$ is $\mathbf{t}$-evidence for $P$, (C*) holds, and yet $R$ is not $\mathbf{t}$-evidence for $P$. Thus, regardless of the value specified for $\mathbf{t}$ $\left(C^{*}\right)$ is not a condition for transitivity in $\mathbf{t}$-evidence. Likewise with respect to $\mathbf{t}^{\prime}$-evidence and $\mathbf{t t}^{\prime}$-evidence.

\footnotetext{
${ }^{3}$ The labels "(C)" and "(TE)" are mine.

${ }^{4}$ Douven also shows that $(\mathrm{C})$ is not a condition for transitivity in $\mathbf{t}(1)$-evidence, $\mathbf{t t}(\mathrm{l})$ evidence, $\mathbf{t}(\mathrm{k})$-evidence, or $\mathbf{t t}(\mathrm{k})$-evidence, where "l" refers to the log-likelihood measure of confirmation and " $k$ " refers to the Kemeny-Oppenheim measure.
} 
2. Consider the condition:

$\left(\mathrm{C}^{* *}\right) \quad \operatorname{Pr}(P \mid R \wedge Q)>\operatorname{Pr}(P \mid Q)$ and $\operatorname{Pr}(P \mid R \wedge \neg Q)>\operatorname{Pr}(P \mid \neg Q)$.

$\left(\mathrm{C}^{* *}\right)$ is stronger than $\left(\mathrm{C}^{*}\right)$, and neither weaker nor stronger than $(\mathrm{C})$.

It can be shown that:

(TE**) If $\operatorname{Pr}(Q \mid R)>\operatorname{Pr}(Q), \operatorname{Pr}(P \mid Q)>\operatorname{Pr}(P)$, and $\left(\mathrm{C}^{* *}\right)$ holds, then $\operatorname{Pr}(P \mid R)>$ $\mathrm{P}(P){ }^{5}$

(C**) fails to hold if (C) holds. So, any probability distribution on which $R$ is tevidence for $Q, Q$ is t-evidence for $P,(\mathrm{C})$ holds, and yet $R$ is not $\mathbf{t}$-evidence for $P$ is a probability distribution on which $\left(\mathrm{C}^{* *}\right)$ fails to hold. Likewise with respect to $\mathbf{t}^{\prime}$-evidence and $\mathbf{t t}^{\prime}$-evidence. Hence, nothing in what Douven says about $(\mathrm{C})$ shows that $\left(\mathrm{C}^{* *}\right)$ is not a condition for transitivity in t-evidence, $\mathbf{t}^{\prime}$-evidence, or $\mathbf{t t}$ '-evidence.

It is relatively straightforward to show, however, that with some specifications for $\mathbf{t}$ and $\mathbf{t}^{\prime}\left(\mathrm{C}^{* *}\right)$ is not a condition for transitivity in $\mathbf{t}$-evidence, $\mathbf{t}^{\prime}$-evidence, or $\mathbf{t t}^{\prime}$-evidence. For example, with $\mathbf{t}^{\prime}=.5$ it follows from the following probability distribution that $\left(\mathrm{C}^{* *}\right)$ is not a condition for transitivity in $\mathbf{t}^{\prime}$-evidence:

\begin{tabular}{ccccccccc}
\hline$P$ & $Q$ & $R$ & $\operatorname{Pr}$ & & $P$ & $Q$ & $R$ & $\operatorname{Pr}$ \\
\cline { 1 - 5 } \cline { 6 - 8 } $\mathrm{T}$ & $\mathrm{T}$ & $\mathrm{T}$ & $\frac{2}{41}$ & & $\mathrm{~F}$ & $\mathrm{~T}$ & $\mathrm{~T}$ & $\frac{1}{214}$ \\
$\mathrm{~T}$ & $\mathrm{~T}$ & $\mathrm{~F}$ & $\frac{1}{901}$ & & $\mathrm{~F}$ & $\mathrm{~T}$ & $\mathrm{~F}$ & $\frac{1}{45}$ \\
$\mathrm{~T}$ & $\mathrm{~F}$ & $\mathrm{~T}$ & $\frac{1}{791}$ & & $\mathrm{~F}$ & $\mathrm{~F}$ & $\mathrm{~T}$ & $\frac{1}{27}$ \\
$\mathrm{~T}$ & $\mathrm{~F}$ & $\mathrm{~F}$ & $\frac{1}{844}$ & & $\mathrm{~F}$ & $\mathrm{~F}$ & $\mathrm{~F}$ & $\frac{314,821,182,887,711}{356,242,003,012,980}$ \\
\hline
\end{tabular}

And with $\mathbf{t}=\mathbf{t}^{\prime}=.5$ it follows from the following probability distribution that $\left(\mathrm{C}^{* *}\right)$ is not a condition for transitivity in $\mathbf{t t}^{\prime}$-evidence:

\footnotetext{
${ }^{5}$ Start with the argument in Roche (2012) for (TPS*). Replace " $z$ " with " $P$," " $y$ " with " $Q$," and " $x$ " with " $R$." Delete (e), (f), and (g). Then modify the remainder of the argument accordingly.
} 


\begin{tabular}{|c|c|c|c|c|c|c|c|}
\hline$P$ & $Q$ & $R$ & $\operatorname{Pr}$ & $P$ & $Q$ & $R$ & $\operatorname{Pr}$ \\
\hline \multirow{2}{*}{$\mathrm{T}$} & \multirow{2}{*}{$\mathrm{T}$} & \multirow{2}{*}{$\mathrm{T}$} & 1 & \multirow{2}{*}{$\mathrm{F}$} & \multirow{2}{*}{$\mathrm{T}$} & \multirow{2}{*}{$\mathrm{T}$} & 1 \\
\hline & & & $\overline{43}$ & & & & $\overline{92}$ \\
\hline \multirow{2}{*}{$\mathrm{T}$} & \multirow{2}{*}{$\mathrm{T}$} & \multirow[t]{2}{*}{$\mathrm{F}$} & 1 & \multirow{2}{*}{$\mathrm{F}$} & \multirow{2}{*}{$\mathrm{T}$} & \multirow{2}{*}{$\mathrm{F}$} & 1 \\
\hline & & & $\overline{165}$ & & & & $\overline{133}$ \\
\hline \multirow{2}{*}{$\mathrm{T}$} & \multirow{2}{*}{$\mathrm{F}$} & \multirow{2}{*}{$\mathrm{T}$} & 1 & \multirow{2}{*}{$\mathrm{F}$} & \multirow{2}{*}{$\mathrm{F}$} & \multirow{2}{*}{$\mathrm{T}$} & 31,847 \\
\hline & & & $\overline{608}$ & & & & $1,202,624$ \\
\hline \multirow{2}{*}{$\mathrm{T}$} & \multirow{2}{*}{$\mathrm{F}$} & \multirow{2}{*}{$\mathrm{F}$} & 1 & \multirow{2}{*}{$\mathrm{F}$} & \multirow{2}{*}{$\mathrm{F}$} & \multirow{2}{*}{$\mathrm{F}$} & $\underline{1,389,286,211}$ \\
\hline & & & $\overline{250}$ & & & & $\overline{1,509,816,000}$ \\
\hline
\end{tabular}

I thank a very generous anonymous reviewer for providing the above two probability distributions (or, strictly speaking, slight variants thereof), and for providing a probability distribution showing that with $\mathbf{t}=.5\left(\mathrm{C}^{* *}\right)$ is not a condition for transitivity in $\mathbf{t}$-evidence. Each of the three distributions was found using the decision procedure PrSAT developed by Branden Fitelson (in collaboration with Jason Alexander and Ben Blum). ${ }^{6}$

I leave it for further investigation whether with certain other specifications for $\mathbf{t}$ and $\mathbf{t}^{\prime}$ $\left(\mathrm{C}^{* *}\right)$ is a condition for transitivity in $\mathbf{t}^{\prime}$-evidence or $\mathbf{t t}^{\prime}$ '-evidence. ${ }^{7} \mathrm{I}$ want to focus on whether with certain other specifications for $\mathbf{t}\left(\mathrm{C}^{* *}\right)$ is a condition for transitivity in $\mathbf{t}-$ evidence. I aim to show that the answer is negative-so that regardless of the value specified for $\boldsymbol{t}\left(\mathrm{C}^{* *}\right)$ is not a condition for transitivity in $\mathbf{t}$-evidence. (For completeness I begin with the case where $\mathbf{t}=.5$. The schema used in addressing that case is also used in addressing the case where $\mathbf{t}>$.5.)

Consider the following schema, where $\alpha, \beta \in \mathbb{R}^{+}$and $\tau=\alpha+(1 / 10)^{\beta}+(1 / 10)^{\beta}+$ $(2 / 10)^{\beta}+(1 / 10)^{\beta}+(9 / 10)^{\beta}+10^{\beta}$ :

\begin{tabular}{ccccccccc}
\hline$P$ & $Q$ & $R$ & $\operatorname{Pr}$ & & $P$ & $Q$ & $R$ & $\operatorname{Pr}$ \\
\cline { 1 - 2 } \cline { 6 - 8 } $\mathrm{T}$ & $\mathrm{T}$ & $\mathrm{T}$ & $\alpha / \tau$ & & $\mathrm{F}$ & $\mathrm{T}$ & $\mathrm{T}$ & $(2 / 10)^{\beta} / \tau$ \\
$\mathrm{T}$ & $\mathrm{T}$ & $\mathrm{F}$ & $(1 / 10)^{\beta} / \tau$ & & $\mathrm{F}$ & $\mathrm{T}$ & $\mathrm{F}$ & $(1 / 10)^{\beta} / \tau$ \\
$\mathrm{T}$ & $\mathrm{F}$ & $\mathrm{T}$ & $(1 / 10)^{\beta} / \tau$ & & $\mathrm{F}$ & $\mathrm{F}$ & $\mathrm{T}$ & $(9 / 10)^{\beta} / \tau$ \\
$\mathrm{T}$ & $\mathrm{F}$ & $\mathrm{F}$ & 0 & & $\mathrm{~F}$ & $\mathrm{~F}$ & $\mathrm{~F}$ & $10^{\beta} / \tau$ \\
\hline
\end{tabular}

${ }^{6}$ See Fitelson (2008) for a description of PrSAT and some applications.

${ }^{7}$ Clearly, the fact that with some specifications for $\mathbf{t}$ and $\mathbf{t}^{\prime}\left(\mathrm{C}^{* *}\right)$ is not a condition for transitivity in $\mathbf{t}^{\prime}$-evidence or 'tt'-evidence leaves it open that with certain other specifications for $\mathbf{t}$ and $\mathbf{t}^{\prime}\left(\mathrm{C}^{* *}\right)$ is a condition for transitivity in $\mathbf{t}^{\prime}$-evidence and $\mathbf{t t}^{\prime}$ evidence. 
Suppose $\mathbf{t}=.5$ and $\alpha=\beta=1$. Then it follows that:

(1) $\operatorname{Pr}(Q \mid R)=\frac{\alpha+\left(\frac{2}{10}\right)^{\beta}}{\alpha+\left(\frac{1}{10}\right)^{\beta}+\left(\frac{2}{10}\right)^{\beta}+\left(\frac{9}{10}\right)^{\beta}}=\frac{1+\frac{2}{10}}{1+\frac{1}{10}+\frac{2}{10}+\frac{9}{10}}=\frac{6}{11}$;

(2) $\operatorname{Pr}(Q)=\frac{\alpha+\left(\frac{1}{10}\right)^{\beta}+\left(\frac{2}{10}\right)^{\beta}+\left(\frac{1}{10}\right)^{\beta}}{\alpha+\left(\frac{1}{10}\right)^{\beta}+\left(\frac{1}{10}\right)^{\beta}+\left(\frac{2}{10}\right)^{\beta}+\left(\frac{1}{10}\right)^{\beta}+\left(\frac{9}{10}\right)^{\beta}+10^{\beta}}=\frac{1+\frac{1}{10}+\frac{2}{10}+\frac{1}{10}}{1+\frac{1}{10}+\frac{1}{10}+\frac{2}{10}+\frac{1}{10}+\frac{9}{10}+10}=\frac{7}{62}$;

(3) $\operatorname{Pr}(P \mid Q)=\frac{\alpha+\left(\frac{1}{10}\right)^{\beta}}{\alpha+\left(\frac{1}{10}\right)^{\beta}+\left(\frac{2}{10}\right)^{\beta}+\left(\frac{1}{10}\right)^{\beta}}=\frac{1+\frac{1}{10}}{1+\frac{1}{10}+\frac{2}{10}+\frac{1}{10}}=\frac{11}{14}$;

(4) $\operatorname{Pr}(P)=\frac{\alpha+\left(\frac{1}{10}\right)^{\beta}+\left(\frac{1}{10}\right)^{\beta}}{\alpha+\left(\frac{1}{10}\right)^{\beta}+\left(\frac{1}{10}\right)^{\beta}+\left(\frac{2}{10}\right)^{\beta}+\left(\frac{1}{10}\right)^{\beta}+\left(\frac{9}{10}\right)^{\beta}+10^{\beta}}=\frac{1+\frac{1}{10}+\frac{1}{10}}{1+\frac{1}{10}+\frac{1}{10}+\frac{2}{10}+\frac{1}{10}+\frac{9}{10}+10}=\frac{3}{31}$;

(5) $\operatorname{Pr}(P \mid R \wedge Q)=\frac{\alpha}{\alpha+\left(\frac{2}{10}\right)^{\beta}}=\frac{1}{1+\frac{2}{10}}=\frac{5}{6}$;

(6) $\operatorname{Pr}(P \mid R \wedge \neg Q)=\frac{\left(\frac{1}{10}\right)^{\beta}}{\left(\frac{1}{10}\right)^{\beta}+\left(\frac{9}{10}\right)^{\beta}}=\frac{\frac{1}{10}}{\frac{1}{10}+\frac{9}{10}}=\frac{1}{10}$;

$$
\operatorname{Pr}(P \mid \neg Q)=\frac{\left(\frac{1}{10}\right)^{\beta}}{\left(\frac{1}{10}\right)^{\beta}+\left(\frac{9}{10}\right)^{\beta}+10^{\beta}}=\frac{\frac{1}{10}}{\frac{1}{10}+\frac{9}{10}+10}=\frac{1}{110}
$$

(8) $\operatorname{Pr}(P \mid R)=\frac{\alpha+\left(\frac{1}{10}\right)^{\beta}}{\alpha+\left(\frac{1}{10}\right)^{\beta}+\left(\frac{2}{10}\right)^{\beta}+\left(\frac{9}{10}\right)^{\beta}}=\frac{1+\frac{1}{10}}{1+\frac{1}{10}+\frac{2}{10}+\frac{9}{10}}=\frac{1}{2}$.

By (1) and (2) it follows that $R$ is t-evidence for $Q$. By (3) and (4) it follows that $Q$ is tevidence for $P$. By (3), (5), (6), and (7) it follows that $\left(\mathrm{C}^{* *}\right)$ holds. By (8) it follows that $R$ is not t-evidence for $P$ because $\operatorname{Pr}(P \mid R) \ngtr \mathbf{t}$. So, with $\mathbf{t}=.5$ there are probability distributions on which $R$ is t-evidence for $Q, Q$ is $\mathbf{t}$-evidence for $P,\left(\mathrm{C}^{* *}\right)$ holds, and yet, though $R$ is evidence for $P, R$ is not t-evidence for $P$ since $\operatorname{Pr}(P \mid R) \ngtr \mathbf{t}$. 
I turn now to the case where $\mathbf{t}>$.5. Suppose $\alpha=1$ and $\beta \geq 1$. The aim is to show that with $\mathbf{t}>.5$ there are probability distributions which are instances of the schema above such that $R$ is $\mathbf{t}$-evidence for $Q, Q$ is $\mathbf{t}$-evidence for $P,\left(\mathrm{C}^{* *}\right)$ holds, and yet, though $R$ is evidence for $P, R$ is not $\mathbf{t}$-evidence for $P$ since $\operatorname{Pr}(P \mid R) \ngtr \mathbf{t}$.

First, observe that each of $\operatorname{Pr}(Q \mid R)$ and $\operatorname{Pr}(P \mid Q)$ approaches 1 as $\beta$ tends to $\infty$ :

(9) $\lim _{\beta \rightarrow \infty} \frac{\alpha+\left(\frac{2}{10}\right)^{\beta}}{\alpha+\left(\frac{1}{10}\right)^{\beta}+\left(\frac{2}{10}\right)^{\beta}+\left(\frac{9}{10}\right)^{\beta}}=1$;

(10) $\lim _{\beta \rightarrow \infty} \frac{\alpha+\left(\frac{1}{10}\right)^{\beta}}{\alpha+\left(\frac{1}{10}\right)^{\beta}+\left(\frac{2}{10}\right)^{\beta}+\left(\frac{1}{10}\right)^{\beta}}=1$.

So, regardless of the value specified for $\mathbf{t}$ there is a value for $\beta$ such that $\operatorname{Pr}(Q \mid R)>\mathbf{t}$ and $\operatorname{Pr}(P \mid Q)>\mathbf{t}$.

The same is true of $\operatorname{Pr}(P \mid R)$, since $\operatorname{Pr}(P \mid R)$, like each of $\operatorname{Pr}(Q \mid R)$ and $\operatorname{Pr}(P \mid Q)$, approaches 1 as $\beta$ tends to $\infty$ :

(11) $\lim _{\beta \rightarrow \infty} \frac{\alpha+\left(\frac{1}{10}\right)^{\beta}}{\alpha+\left(\frac{1}{10}\right)^{\beta}+\left(\frac{2}{10}\right)^{\beta}+\left(\frac{9}{10}\right)^{\beta}}=1$.

But, crucially, the following inequalities hold:

(12) $\operatorname{Pr}(Q \mid R)-\operatorname{Pr}(P \mid R)>0$;

(13) $\operatorname{Pr}(P \mid Q)-\operatorname{Pr}(P \mid R)>0$.

That (12) holds can be seen by verifying that:

$$
\begin{aligned}
\operatorname{Pr}(Q \mid R)-\operatorname{Pr}(P \mid R)=\frac{\alpha+\left(\frac{2}{10}\right)^{\beta}}{\alpha+\left(\frac{1}{10}\right)^{\beta}+\left(\frac{2}{10}\right)^{\beta}+\left(\frac{9}{10}\right)^{\beta}}-\frac{\alpha+\left(\frac{1}{10}\right)^{\beta}}{\alpha+\left(\frac{1}{10}\right)^{\beta}+\left(\frac{2}{10}\right)^{\beta}+\left(\frac{9}{10}\right)^{\beta}} & =\frac{\left(\frac{2}{10}\right)^{\beta}-\left(\frac{1}{10}\right)^{\beta}}{\alpha+\left(\frac{1}{10}\right)^{\beta}+\left(\frac{2}{10}\right)^{\beta}+\left(\frac{9}{10}\right)^{\beta}}>0 .
\end{aligned}
$$


That (13) holds is clear:

$$
\operatorname{Pr}(P \mid Q)-\operatorname{Pr}(P \mid R)=\frac{\alpha+\left(\frac{1}{10}\right)^{\beta}}{\alpha+\left(\frac{1}{10}\right)^{\beta}+\left(\frac{2}{10}\right)^{\beta}+\left(\frac{1}{10}\right)^{\beta}}-\frac{\alpha+\left(\frac{1}{10}\right)^{\beta}}{\alpha+\left(\frac{1}{10}\right)^{\beta}+\left(\frac{2}{10}\right)^{\beta}+\left(\frac{9}{10}\right)^{\beta}}>0 .
$$

Next, consider the inequalities:

(14) $\operatorname{Pr}(Q \mid R)-\operatorname{Pr}(Q)>0$;

(15) $\operatorname{Pr}(P \mid Q)-\operatorname{Pr}(P)>0$.

I noted above that each of $\operatorname{Pr}(Q \mid R)$ and $\operatorname{Pr}(P \mid Q)$ approaches 1 as $\beta$ tends to $\infty$. This is not true of $\operatorname{Pr}(Q)$ and $\operatorname{Pr}(P)$ - quite the opposite in fact. Each of $\operatorname{Pr}(Q)$ and $\operatorname{Pr}(P)$ approaches 0 as $\beta$ tends to $\infty$ :

(16) $\lim _{\beta \rightarrow \infty} \frac{\alpha+\left(\frac{1}{10}\right)^{\beta}+\left(\frac{2}{10}\right)^{\beta}+\left(\frac{1}{10}\right)^{\beta}}{\alpha+\left(\frac{1}{10}\right)^{\beta}+\left(\frac{1}{10}\right)^{\beta}+\left(\frac{2}{10}\right)^{\beta}+\left(\frac{1}{10}\right)^{\beta}+\left(\frac{9}{10}\right)^{\beta}+10^{\beta}}=0$;

(17) $\lim _{\beta \rightarrow \infty} \frac{\alpha+\left(\frac{1}{10}\right)^{\beta}+\left(\frac{1}{10}\right)^{\beta}}{\alpha+\left(\frac{1}{10}\right)^{\beta}+\left(\frac{1}{10}\right)^{\beta}+\left(\frac{2}{10}\right)^{\beta}+\left(\frac{1}{10}\right)^{\beta}+\left(\frac{9}{10}\right)^{\beta}+10^{\beta}}=0$.

I showed above that with $\alpha=\beta=1, \operatorname{Pr}(Q \mid R)>\operatorname{Pr}(Q)$ and $\operatorname{Pr}(P \mid Q)>\operatorname{Pr}(P)$. So, given (9), (10), (16), and (17), and with $\alpha=1$ and $\beta \geq 1$, it follows that (14) and (15) hold.

It remains to be shown that $\left(\mathrm{C}^{* *}\right)$ holds. First, verify that:

$$
\begin{array}{r}
\operatorname{Pr}(P \mid R \wedge Q)-\operatorname{Pr}(P \mid Q)=\frac{\alpha}{\alpha+\left(\frac{2}{10}\right)^{\beta}}-\frac{\alpha+\left(\frac{1}{10}\right)^{\beta}}{\alpha+\left(\frac{1}{10}\right)^{\beta}+\left(\frac{2}{10}\right)^{\beta}+\left(\frac{1}{10}\right)^{\beta}} \\
=\frac{\left[\alpha^{2}+\alpha\left(\frac{1}{10}\right)^{\beta}+\alpha\left(\frac{2}{10}\right)^{\beta}+\alpha\left(\frac{1}{10}\right)^{\beta}\right]-\left[\alpha^{2}+\alpha\left(\frac{2}{10}\right)^{\beta}+\alpha\left(\frac{1}{10}\right)^{\beta}+\left(\frac{1}{10}\right)^{\beta}\left(\frac{2}{10}\right)^{\beta}\right]}{\left[\alpha+\left(\frac{2}{10}\right)^{\beta}\right]\left[\alpha+\left(\frac{1}{10}\right)^{\beta}+\left(\frac{2}{10}\right)^{\beta}+\left(\frac{1}{10}\right)^{\beta}\right]} \\
=\frac{\alpha\left(\frac{1}{10}\right)^{\beta}-\left(\frac{1}{10}\right)^{\beta}\left(\frac{2}{10}\right)^{\beta}}{\left[\alpha+\left(\frac{2}{10}\right)^{\beta}\right]\left[\alpha+\left(\frac{1}{10}\right)^{\beta}+\left(\frac{2}{10}\right)^{\beta}+\left(\frac{1}{10}\right)^{\beta}\right]}>0 .
\end{array}
$$


Next, observe that:

(19) $\operatorname{Pr}(P \mid R \wedge \neg Q)-\operatorname{Pr}(P \mid \neg Q)=\frac{\left(\frac{1}{10}\right)^{\beta}}{\left(\frac{1}{10}\right)^{\beta}+\left(\frac{9}{10}\right)^{\beta}}-\frac{\left(\frac{1}{10}\right)^{\beta}}{\left(\frac{1}{10}\right)^{\beta}+\left(\frac{9}{10}\right)^{\beta}+10^{\beta}}>0$.

So, $\left(\mathrm{C}^{* *}\right)$ holds.

The aim, recall, is to show that with $\mathbf{t}>.5$ there are probability distributions which are instances of the schema above such that $R$ is $\mathbf{t}$-evidence for $Q, Q$ is $\mathbf{t}$-evidence for $P$, (C**) holds, and yet, though $R$ is evidence for $P, R$ is not t-evidence for $P$ since $\operatorname{Pr}(P \mid R)$ $\ngtr \mathbf{t}$. Take $\alpha=\beta=1$. Then, as shown above (for the case where $\mathbf{t}=.5$ ), it follows that $\operatorname{Pr}(Q$ $\mid R)=6 / 11>\operatorname{Pr}(Q)=7 / 62, \operatorname{Pr}(P \mid Q)=11 / 14>\operatorname{Pr}(P)=3 / 31,\left(\mathrm{C}^{* *}\right)$ holds, and $\operatorname{Pr}(P \mid R)=$ $1 / 2$. If $6 / 11>\mathbf{t}>.5$, it follows that the probability distribution in question is a probability distribution which is an instance of the schema above such that $R$ is t-evidence for $Q, Q$ is t-evidence for $P,\left(\mathrm{C}^{* *}\right)$ holds, and yet, though $R$ is evidence for $P, R$ is not $\mathbf{t}$-evidence for $P$ since $\operatorname{Pr}(P \mid R) \ngtr \mathbf{t}$. If, instead, $\mathbf{t} \geq 6 / 11$, then let the value of $\beta$ increase until $\operatorname{Pr}(Q \mid R)>$ $\mathbf{t}$ and $\operatorname{Pr}(P \mid Q)>\mathbf{t}$ but $\operatorname{Pr}(P \mid R) \ngtr \mathbf{t}$; that there is such a value for $\beta$ is guaranteed by (9), (10), (12), and (13). It will still be the case that $\operatorname{Pr}(Q \mid R)>\operatorname{Pr}(Q), \operatorname{Pr}(P \mid Q)>\operatorname{Pr}(P)$, and $\left(C^{* *}\right)$ holds; this follows from (14), (15), (18), and (19). So, the probability distribution in question will be a probability distribution which is an instance of the schema above such that $R$ is t-evidence for $Q, Q$ is t-evidence for $P,\left(\mathrm{C}^{* *}\right)$ holds, and yet, though $R$ is evidence for $P, R$ is not $\mathbf{t}$-evidence for $P$ since $\operatorname{Pr}(P \mid R) \ngtr \mathbf{t}$.

The result is that regardless of the value specified for $\mathbf{t}$, that is, regardless of whether $\mathbf{t}$ $=.5$ or $\mathbf{t}>.5,\left(\mathrm{C}^{* *}\right)$ is not a condition for transitivity in $\mathbf{t}$-evidence.

3. In section 1 , I argued that, though $\left(\mathrm{C}^{*}\right)$ is a condition for transitivity in evidence, $\left(\mathrm{C}^{*}\right)$ is not a condition for transitivity in $\mathbf{t}$-evidence, $\mathbf{t}^{\prime}$-evidence, or $\mathbf{t} \mathbf{t}^{\prime}$-evidence. In section $2, \mathrm{I}$ argued that, though $\left(\mathrm{C}^{* *}\right)$ is a condition for transitivity in evidence, $\left(\mathrm{C}^{* *}\right)$ is not a condition for transitivity in t-evidence. I now aim to show that there $i s$ a condition for transitivity in $\mathbf{t}$-evidence (regardless of the value specified for $\mathbf{t}$, but given the constraint that $1>\mathbf{t} \geq .5$ ).

The condition is:

$$
\left(\mathrm{C}^{* * *}\right) \quad \operatorname{Pr}(P \mid R \wedge Q) \geq \operatorname{Pr}(P \mid Q), \operatorname{Pr}(P \mid R \wedge \neg Q) \geq \operatorname{Pr}(P \mid \neg Q) \text {, and } Q \text { entails } P .
$$


The aim is to show:

(TE***) If $R$ is t-evidence for $Q, Q$ is t-evidence for $P$, and ( $\left.\mathrm{C}^{* * *}\right)$ holds, then $R$ is t-evidence for $P$.

Three comments. First, $\left(\mathrm{C}^{* * *}\right)$ is simply the conjunction of $\left(\mathrm{C}^{*}\right)$ and the condition that $Q$ entails $P$. Second, $\left(\mathrm{C}^{* * *}\right)$ could instead be put as: $\operatorname{Pr}(P \mid R \wedge \neg Q) \geq \operatorname{Pr}(P \mid \neg Q)$ and $Q$ entails $P$. When $Q$ entails $P$, it follows that $\operatorname{Pr}(P \mid R \wedge Q)=\operatorname{Pr}(P \mid Q)=1$, hence $\operatorname{Pr}(P \mid R \wedge$ $Q) \geq \operatorname{Pr}(P \mid Q)$. Third, (TE***) could instead be put as: If $R$ is t-evidence for $Q, Q$ entails $P, \operatorname{Pr}(P)<1$, and $\left(\mathrm{C}^{*}\right)$ holds, then $R$ is t-evidence for $P$. If $Q$ is t-evidence for $P$ and $\left(\mathrm{C}^{* * *}\right)$ holds, then $Q$ entails $P, \operatorname{Pr}(P)<1$, and $\left(\mathrm{C}^{*}\right)$ holds, and vice versa.

Suppose, now, (a) $R$ is t-evidence for $Q$, thus (a1) $\operatorname{Pr}(Q \mid R)>\operatorname{Pr}(Q)$ and (a2) $\operatorname{Pr}(Q \mid R$ ) $>\mathbf{t}$. Suppose (b) $Q$ is t-evidence for $P$, hence (b1) $\operatorname{Pr}(P \mid Q)>\operatorname{Pr}(P)$ and (b2) $\operatorname{Pr}(P \mid Q)>\mathbf{t}$. Suppose (c) (C***) holds, thus (c1) (C*) holds and (c2) $Q$ entails $P$. By (a1), (b1), (c1), and $\left(\mathrm{TE}^{*}\right)$, it follows that $\operatorname{Pr}(P \mid R)>\mathrm{P}(P)$. By (c2) and the theorem that if $Q$ entails $P$, then $\operatorname{Pr}(P \mid R) \geq \operatorname{Pr}(Q \mid R)$, it follows that $\operatorname{Pr}(P \mid R) \geq \operatorname{Pr}(Q \mid R)$. By (a2), it then follows that $\operatorname{Pr}(P \mid R)>\mathbf{t}$. Thus, since $\operatorname{Pr}(P \mid R)>\mathrm{P}(P)$ and $\operatorname{Pr}(P \mid R)>\mathbf{t}$, it follows that $R$ is tevidence for $P$. So, $\left(\mathrm{TE}^{* * *}\right)$.

Let's consider an example. Suppose $\mathbf{t}=.7$. Suppose we have a nonstandard deck of cards, in that there are 100 cards in the deck, 50 of the cards are heart (hence red) court cards, 15 of the cards are diamond (thus red) court cards, 20 of the cards are diamond non-court cards, 5 of the cards are black court cards, and 10 of the cards are black noncourt cards. Suppose we randomly draw a card from the deck. Let $R$ be the claim that the card drawn is a court card, $Q$ be the claim that the card drawn is a heart, and $P$ be the claim that the card drawn is a red card. Suppose, then, the following probability distribution:

\begin{tabular}{|c|c|c|c|c|c|c|c|}
\hline$P$ & $Q$ & $R$ & $\mathrm{Pr}$ & $P$ & $Q$ & $R$ & $\mathrm{Pr}$ \\
\hline $\mathrm{T}$ & $\mathrm{T}$ & $\mathrm{T}$ & .5 & $\mathrm{~F}$ & $\mathrm{~T}$ & $\mathrm{~T}$ & 0 \\
\hline $\mathrm{T}$ & $\mathrm{T}$ & $\mathrm{F}$ & 0 & $\mathrm{~F}$ & $\mathrm{~T}$ & $\mathrm{~F}$ & 0 \\
\hline $\mathrm{T}$ & $\mathrm{F}$ & $\mathrm{T}$ & .15 & $\mathrm{~F}$ & $\mathrm{~F}$ & $\mathrm{~T}$ & .05 \\
\hline $\mathrm{T}$ & $\mathrm{F}$ & $\mathrm{F}$ & .2 & $\mathrm{~F}$ & $\mathrm{~F}$ & $\mathrm{~F}$ & .1 \\
\hline
\end{tabular}

Then: 


$$
\begin{aligned}
& \operatorname{Pr}(Q \mid R) \approx .714>\operatorname{Pr}(Q)=.5 ; \\
& \operatorname{Pr}(P \mid Q)=1>\operatorname{Pr}(P)=.85 ; \\
& \operatorname{Pr}(P \mid R \wedge Q)=1 \geq \operatorname{Pr}(P \mid Q)=1 ; \\
& \operatorname{Pr}(P \mid R \wedge \neg Q)=.75 \geq \operatorname{Pr}(P \mid \neg Q)=.7 ; \\
& \operatorname{Pr}(P \mid R) \approx .929>\operatorname{Pr}(P)=.85 .
\end{aligned}
$$

$R$ is t-evidence for $Q, Q$ is t-evidence for $P,\left(\mathrm{C}^{* * *}\right)$ holds, and, as (TE***) implies, $R$ is t-evidence for $P$.

Two final points are in order. First, there is a clear sense in which (TE***) is a "transmission" principle as opposed to a "closure" principle. Consider the principle:

$$
\text { If } \operatorname{Pr}(Q \mid R)>\mathbf{t} \text {, and } Q \text { entails } P \text {, then } \operatorname{Pr}(P \mid R)>\mathbf{t} \text {. }
$$

(CE) is a closure principle. ${ }^{8}$ It can be understood as saying that (where $\mathbf{t}$ is the threshold for rational acceptability) if $Q$ is rationally acceptable given $R$, and $Q$ entails $P$, then $P$ is rationally acceptable given $R$. All positive instances of (CE) are thus cases in which $P$ is rationally acceptable given $R$. Some such cases, though, are cases in which $R$ is evidence against $P$ in that $\operatorname{Pr}(P \mid R)<\operatorname{Pr}(P)$. By contrast, all positive instances of (TE***) are cases in which (a) $P$ is rationally acceptable given $R$ and (b) $R$ is evidence for $P$ in that $\operatorname{Pr}(P \mid R)>\operatorname{Pr}(P) .{ }^{9}$ Second, though all positive instances of (TE***) are cases in which $P$ is evidence for $R$ in that $\operatorname{Pr}(P \mid R)>\operatorname{Pr}(P)$, it does not follow that all positive instances of (TE***) are cases in which $\operatorname{Pr}(P \mid R)-\operatorname{Pr}(P) \geq \operatorname{Pr}(Q \mid R)-\operatorname{Pr}(Q)$. In fact, some positive

\footnotetext{
${ }^{8}$ See Chandler (2010, p. 337, n. 5).

${ }^{9} \mathrm{I}$ leave it for further investigation how $\left(\mathrm{C}^{* * *}\right)$ and $\left(\mathrm{TE}^{* * *}\right)$ relate to the issue Crispin Wright $(2002,2003)$ has in mind in speaking of when it is that warrant transmits across entailment. For discussion of how to formalize the issue Wright has in mind, see Chandler (2010), Moretti (2010), and Okasha (2004). Cf. Pynn (2011).
} 
instances of (TE***) are cases in which $\operatorname{Pr}(P \mid R)-\operatorname{Pr}(P)<\operatorname{Pr}(Q \mid R)-\operatorname{Pr}(Q) .{ }^{10}$ The case given in the prior paragraph is a case in point; $\operatorname{Pr}(P \mid R)-\operatorname{Pr}(P) \approx .079<\operatorname{Pr}(Q \mid R)-\operatorname{Pr}(Q)$ $\approx .214 .^{11}$

\section{References}

Chandler, J. (2010). The transmission of support: a Bayesian re-analysis. Synthese, 176, $333-343$.

Douven, I. (2011). Further results on the intransitivity of evidential support. Review of Symbolic Logic, forthcoming.

Eells, E., \& Sober, E. (1983). Probabilistic causality and the question of transitivity. Philosophy of Science, 50, 35-57.

Fitelson, B. (2008). A decision procedure for probability calculus with applications. Review of Symbolic Logic, 1, 111-125.

Hanen, M. (1971). Confirmation and adequacy conditions. Philosophy of Science, 38, 361-368.

Hesse, M. (1970). Theories and the transitivity of confirmation. Philosophy of Science, 37, 50-63.

Moretti, L. (2010). Wright, Okasha and Chandler on transmission failure. Synthese, forthcoming.

Okasha, S. (2004). Wright on the transmission of support: a Bayesian analysis. Analysis, 64, 139-146.

Pynn, G. (2011). The Bayesian explanation of transmission failure. Synthese, forthcoming.

Roche, W. (2012). A weaker condition for transitivity in probabilistic support. European Journal for Philosophy of Science, 2, 111-118.

Shogenji, T. (2003). A condition for transitivity in probabilistic support. British Journal for the Philosophy of Science, 54, 613-616.

${ }^{10}$ More generally, there are cases in which $\operatorname{Pr}(Q \mid R)>\operatorname{Pr}(Q), Q$ entails $P,\left(\mathrm{C}^{*}\right)$ holds, and yet, though $\operatorname{Pr}(P \mid R)>\operatorname{Pr}(P), \operatorname{Pr}(P \mid R)-\operatorname{Pr}(P)<\operatorname{Pr}(Q \mid R)-\operatorname{Pr}(Q)$. I owe this point to Tomoji Shogenji.

${ }^{11}$ I wish to thank Igor Douven, Tomoji Shogenji, and an anonymous reviewer for helpful comments on a prior version of this paper. 
Wright, C. (2002). (Anti-)sceptics simple and subtle: G. E. Moore and John McDowell. Philosophy and Phenomenological Research, 65, 330-348.

Wright, C. (2003). Some reflections on the acquisition of warrant by inference. In S. Nuccetelli, editor. New Essays on Semantic Externalism and Self-Knowledge. Cambridge, Mass.: MIT Press, pp. 57-77. 